http://dx.doi.org/10.21611/qirt.2015.0160

\title{
Characterization of Low Velocity Impact Damages in Advanced Ceramic Matrix Composites with Infrared Thermography
}

\author{
S. Kalyana Sundaram, S. Kshama, Aparna Gajendragadkar, A. Udayakumar, V.R. Ranganath \\ CSIR-National Aerospace Laboratories, Bengaluru -560017, India. \\ Email : kalyan@nal.res.in
}

\begin{abstract}
Ceramic matrix composite materials such as $\mathrm{SiC}-\mathrm{SiC}, \mathrm{C}_{\mathrm{f}}-\mathrm{SiC}$ are considered as high performance materials and widely used in fabrication of hot-end aero engine components, structural parts of hypersonic vehicles and fabrication of nuclear reactor core components etc. Most of the time, this class of materials face hostile environments where the operating parameters are so complex like high temperature, thermal cycling, thermo-mechanical cycling etc. Hence, presence of fabrication defects and operational damages such as low velocity impact etc on these materials would lead to severe consequences of damages. An early detection of defect generation with reliable NDE methods can assist in design/operation related decision making.
\end{abstract}

Research paper presented here provides technical details of Infrared Thermography based evaluation of $\mathrm{C}_{\mathrm{f}}-\mathrm{SiC}$ composite materials induced with low velocity impact damages. Focus here is to detect the delamination, fibre failure, matrix failure and quantification of damages. Low velocity impacts were imposed with semi-spherical end impactor on the CMC laminate specimens to simulate BVID, laminate tearing, and wide spread delamination etc. Transient IRT with infrared heating source has been used in this evaluation. Captured images were analyzed with image processing tools developed in Matlab platform. Results of IRT based evaluation of $\mathrm{C}_{\mathrm{f}}-\mathrm{SiC}$ CMC materials shows, this to be a potential process for NDE of CMC laminates.

Keywords : Ceramic matrix composite, impact damage, delamination, BVID, thermography 